\title{
APLIKASI BEBERAPA EKSTRAK TANAMAN SEBAGAI BAHAN PERANGKAP LALAT BUAH (Bactrocera sp.)
}

\author{
Sri wahyuni, Petrus Baka Deornay \\ Program Studi Agroteknologi, Fakultas Pertanian Universitas Flores \\ Jln. Sam Ratulangi, Kel. Paupire, Kab. Ende \\ sriwahyuni4611@gmail.com
}

\begin{abstract}
ABSTRCT
Application Some Extracts of plant as Trap Material of Fruit Flies (Bactrocera sp). This study aims to determine: 1) the ability of Pala, Basil and Clove seed extract as a trap material for Bactrocera sp. 2) the best plant extract as a trap material for Bactrocera sp. The extraction activity was carried out at the Laboratory of the Faculty of Agriculture, University of Flores, while the fruit fly trap installation was carried out in Ndengga Rongge Village $( \pm 913 \mathrm{~m}$ asl) and Lokoboko ( $\pm 698 \mathrm{~m}$ asl) in Ende Regency. The study was conducted for 3 months, namely in April - June 2018. Observation variables used included the types of fruit fly found in the field and calculated the level of diversity, abundance and dominance of pests and the capture power of each trap in the type of extraction. There are three types of fruit flies trapped in 3 types of attractants in tomato plantations, namely Bactrocera papaya, Bactrocera umbrosa Fabricius and Bactrocera latifrons Handel. Diversity index of Bactrocera sp. in the research location is still relatively low. The highest abundance is B.papayae with the average value of $H{ }^{\prime}=1.86$ and the lowest is B.latifros $\left(H^{\prime}=0,07\right)$. There is no dominance of type at research location which indicates that the condition of the ecosystem is still stable. Nutmeg extract is the best attractant trap material as an attractant material in field flies
\end{abstract}

Key Words : Ekstract of nutmag, Trap, Bactrocera sp.

\section{PENDAHULUAN}

Lalat buah (Bactrocera sp)

merupakan salah satu jenis hama penting yang berasosiasi pada buah-buahan dan menyerang langsung pada bagian tanaman yang dipanen. Serangan lalat buah dimuali pada saat tanaman memasuki fase awal pembuahan hingg masa panen, dengan gejala adanya bekas tusukan hingga buah busuk dan gugur.

Penelitian tentang keberadaan dan keragaman lalat buah telah banyak dilakukan dan dilaporkan seperti di Asia terdapat 180 jenis, di daerah Indo-Pasifik terdapat 90 jenis, dan di Indonesia bagian barat terdapat 90 jenis (Siwi dan Hidayat, 2004). Di Indonesia bagian barat terdapat 89 spesies lalat buah yang termasuk jenis lokal (indiginous) tetapi hanya delapan spesies yang menjadi hama penting yaitu Bactrocera albistrigata (Meijere), Bactrocera dorsalis Hendel, Bactrocera carambolae Drew and Hancock, Bactrocera papayae Drew and Hancock, Bactrocera umbrosa (Fabricius), Bactrocera caudata (Fabricius), Bactrocera tasu (Walker), Bactrocera cucurbitae 
(Conquillet), dan Dacus (Callantra) longicornis (Wiedemann) (Sunarno dan Popoko 2013).

Gejala serangan lalat buah timbul akibat imago menusukkan ovipositornya ke dalam buah untuk meletakkan telur. Larva yang menetas di dalam buah inilah yang menimbulkan kerusakan berupa buah matang sebelum waktunya, buah membusuk dan akhirnya gugur (Lubis, 2018). Sunarno (2011) melaporkan bahwa serangan hama lalat buah dapat menyebabkan kerugian hingga mencapai $30-60 \%$. Luas serangan lalat buah di Indonesia pada tahun 2003 mencapai 4.790 ha dengan kerugian mencapai 21,99 miliar rupiah (Balitro, 2008). Khusus untuk komoditi jeruk di daerah Karo pada tahun 2012 dilaporkan sekitar 17.000 ha tanaman jeruk mengalami kerusakan sehingga produktivitasnya mengalami penurunan dari 60 ton/ha menjadi 20 ton/ha (Marpaung dkk, 2014). Kondisi lain yang perlu diwaspadai akibat adanya serangan lalat buah adalah penyebaran bakteri Escherichia coli yang terbawa oleh lalat buah dan dapat menyebabkan penyakit pada manusia (Sunarno dan Popoko, 2013).

Teknik pengendalian lalat buah yang dapat dilakukan diantaranya pembungkusan buah, pengasapan, sanitasi kebun, dan penggunaan perangkap (atraktan) dengan menggunakan metil eugenol (Kardinan, 2007). Perangkap metil eugenol memiliki beberapa kelebihan seperti murah, mudah cara pembuatannya, tidak merusak biologis atau tidak menimbulkan resistensi lalat buah serta spesifik terhadap serangga sasaran (Suputa dkk, 2007)

Zat atraktan teknis dapat dengan mudah diperoleh dari toko - toko pertanian, namun demikian peluang untuk mendapatkan zat atraktan dari beberapa jenis tanaman yang terdapat disekitar kita juga dapat diexplor. Beberapa jenis tumbuhan yang memiliki aktivitas atraktan adalah daun selasih (Ocimum santum), biji pala (Myristica fragrans) dan cengkeh (Eugenia aromatica L.). Ekstrak daun selasih, biji pala dan cengkeh mengandung minyak atsiri sebagai indikasi adanya kandungan bahan aktif metil eugenol (Zubaidah, 2008).

Metil eugenol dikenal sebagai senyawa semio chemicals yang memiliki efek atraktan pada lalat buah jantan dari genus Bactocera sp. dalam jumlah banyak. Semio cemical merangsang olfactory serangga yang dapat mempengaruhi tingkah laku hewan serangga seperti perilaku mencari makan, meletakan telur, hubungan seksual dan lainnya (Kardinan, 2003). Penelitian tentang ekstrak daun selasih, biji pala dan cengkeh yang dicobakan pada lalat buah dan kutu beras membuktikan bahwa ketiga jenis tanaman tersebut memiliki kandungan metil eugenol yang dapat berfungsi sebagai jenis insektisida atraktan (Zubaidah, 2008; Andri, 2013), namun demikian sejauh ini belum diketahui bagaimana efek atraktan terbaik dari ketiga jenis ekstrak tersebut terhadap lalat buah di lapang.

\section{METODE PENELITIAN Waktu dan Tempat}

Kegiatan pembuatan ekstrak dilakukan di Laboratorium Fakultas Pertanian, Universitas Flores, sedangkan untuk pemasang perangkap lalat buah dilakukan di Desa Ndengga Rongge ( $\pm 913 \mathrm{~m} \mathrm{dpl}$ ) dan Lokoboko $( \pm 698$ $m$ dpl) Kabupaten Ende. Penelitian dilakukan pada bulan April 2018 - Juni 2018. 


\section{Bahan dan Alat}

Bahan yang digunakan adalah biji pala, daun selasih, bunga cengkeh kering, etanol $96 \%$, es batu, kertas label, tisu, kertas saring whiteman, botol bekas air mineral ukuran $1500 \mathrm{ml}$, kawat, kapas 1,0 gr (steril), dan air bersih. Alat yang digunakan yaitu : Vaccum rotari evaporator, blender, pisau, gelas ukur, corong, talenan, timbangan, tang potong, paku, gunting, pisau cuter, spoid ukuran $1 \mathrm{ml}$, spidol, pulpen dan camera.

\section{Rancangan Penelitian}

Rancangan yang digunakan adalah Rancangan Acak Kelompok dengan 4 perlakuan yaitu E0= Etanol (Kontrol), E1= Ekstrak biji pala , E2 = Ekstrak daun selasih, E3 = Ekstrak bunga cengkeh. Setiap perlakuan diulang sebanyak 3 kali.

\section{Pelaksanaan Penelitian}

\section{Pembuatan Ekstrak Tanaman}

Biji pala daun selasih dan bunga cengkeh masing - masing ditimbang sebanyak $0,25 \mathrm{~kg}$ kemudian di Rajang dan dikeringanginkan \pm 2 hari yang selanjutnya di blender hingga jadi serbuk. Serbuk direndam dengan Etanol 96 $\% \pm 3$ hari setelah itu di saring menggungakan kertas saring/whiteman, selanjutnya proses ekstrasi menggunakan Vaccum rotari evaporator.

\section{Aplikasi Ekstrak Tanaman Sebagai Bahan Perangkap Lalat Buah. \\ Ekstrak bahan disuntikan ke kapas yang ada di dalam botol perangkap masing-masing sebanyak $4 \mathrm{ml}$. Selanjutnya air bersih dimasukan secukupnya ke dalam botol dan tidak boleh mengenai kapas yang telah diberi}

ekstrak. Satu perangkap diperuntukkan bagi 6 tanaman.

\section{Variabel Pengamatan}

Pengamatan dilakukan dua hari sekali, sebanyak tiga kali selama satu minggu masa pemasangan perangkap di lapangan. Data yang terkumpul selanjutnya di analisis menggunakan rumus indeks keragaman, kelimpahan dan dominasi (Mogurron, 2004 dalam Wahyuni, 2017).

1. Identifikasi lalat buah

Lalat buah yang terperangkap dibawa ke laboratorium untuk diidentifikasi dan dihitung jumlahnya. Identifikasi lalat buah dilakukan dengan menggunakan kunci dikotom (Drew 1994; Siwi et al. 2004; ICMPFF 2012), juga kunci identifikasi lalat buah (Diptera: Tephritidae) di beberapa kabupaten di Provinsi Sulawesi Barat (Khaeruddin, 2015) dan Buku Pedoman Koleksi dan Prevarasi Lalat Buah (Suputa dkk, 2007),

\section{Indeks Keragaman}

Pengamatan indeks keragaman dilakukan dengan cara menjumlahkan seluruh jenis yang di peroleh pada semua perlakuan dan ulangan dan di hitung menggunakan rumus :

$$
\mathbf{H}^{1}=-\sum \mathbf{P i} \ln \mathrm{Pi} \operatorname{dimana} \mathbf{P i}=\mathbf{n i} / \mathbf{N}
$$

Keterangan :

$\mathrm{H}^{1}$ : Indeks keragaman

Pi : Proporsi jenis ke-i

ni : Jumlah individu jenis ke-I

$\mathrm{N}$ : Total jumlah individu 
Kriteria:

$\mathrm{H}^{1}<1,0=$ rendah

$\mathrm{H}^{1}=1,0-3=$ sedang

$\mathrm{H}^{1}>3=$ tinggi

3. Indeks Kelimpahan

Pengamatan indeks kelimpahan dilakukan dengan cara membandingkan populasi dari seluruh jenis yang di peroleh pada semua perlakuan dan ulangan dan di hitung menggunakan rumus :

$R_{1}=\frac{S-1}{\operatorname{Ln} \cdot N}$

Keterangan :

$\mathrm{R}_{1: \text { Indeks kelimpahan }}$

$\mathrm{S}$ : jumlah jenis yang ditemukan

$\mathrm{N}$ : Jumlah total individu

Kriteria :

$\mathrm{R}_{1}:<3,5$ (rendah)

$\mathrm{R}_{1}: 3,6-5,0$ (sedang)

$\mathrm{R}_{1}:>5,0$ (tinggi)

\section{Dominasi}

Pengamatan indeks dominasi dilakukan dengan cara menjumlahkan dan membandingkan seluruh jenis yang di peroleh pada semua perlakuan serta ulangan dan di hitung menggunakan rumus :

$\sum \frac{\mathrm{Ni}(\mathrm{Ni}-\mathbf{1})}{\mathrm{N}(\mathrm{N}-\mathbf{1})}$

Keterangan :

D : Indeks dominasi

$\mathrm{Ni}$ : Jumlah individu jenis ke-i

$\mathrm{N}$ : Total jumlah individu
Kriteria : $\mathrm{D}: \leq 0,00-0,30$ (rendah) $\mathrm{D}:>$

$0,31-0,6$ (sedang) $\quad \mathrm{D}:>0,6-1,00$ (tinggi)

\section{Analisis Data}

Untuk mengetahui jenis ekstrak atau perangkap terbaik maka dilakukan analisis data menggunakan uji $\mathrm{F}$ yang sebelumnya di transformasi dengan menggunakan transformasi akar kuadrat $\sqrt{ } \mathrm{x}+0,5$. Apabila uji $\mathrm{F}$ berpengaruh nyata maka akan dilanjutkan dengan uji BNT taraf 5\% ( Gomez \& Gomez, 2010 ).

\section{HASIL DAN PEMBAHASAN}

Jenis lalat buah pada tanaman tomat.

Terdapat 3 (tiga) jenis lalat buah pada tanaman tomat yang ditemukan dilokasi penelitian yaitu :

1. Bactrocera papaya Drew and Hancock

Pengamatan menggunakan mikroskop memperlihatkan adanya mata majemuk yang terdapat pada bagian caput, rambut vertikal, dan rambut genal (Gambar 1b), torax berwarana hitam, rambut skapular, postsutural vita berwaran kuning kecoklatan, terdapat bulu-bulu atau supra alar disisi anterior, terdapat postsutural vittae lateral berwarna kuning tetapi tidak terdapat postsutural vittae median pada bagian tengah torax (Gambar 1c) sayap berpola dengan selaput tipis dan sangat transparan, terdapat garis hitam tebal di bagian luar sayap yang disebut sebagai pita kostal yang memanjang hingga mencapai ujung sayap (Gambar 1d) Abdomen berwarna kuning kecoklatan, terdapat garis hitam pada adomen yang menyerupai huruf (T) atau medial longitudinal pada terga terlihat jelas (Gambar 
1e), kondisi yang sama juga diterangkan oleh

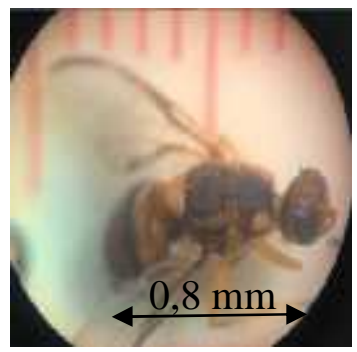

a. Gambar utuh

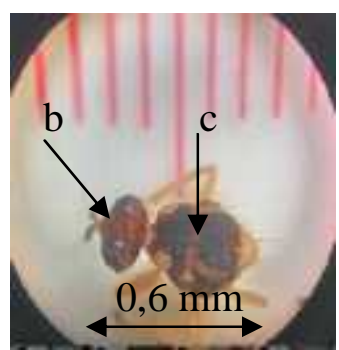

b.Caput c.Thorax
Siwi et al. (2006) dan Suputa et al (20007).

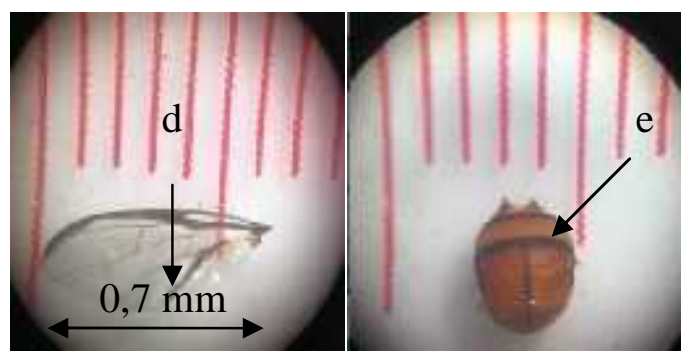

d. Sayap

e. Abdomen

Gambar 1 Bactrocera papayae (dok.pribadi, perbesaran 10x)

2. Bactrocera umbrosa Fabricius.

Pengamatan

menggunakan

mikroskop, terlihat bulatan facial berwarna hitam pada muka di bagian kepala atau caput (Gambar 2b), thorax berwarna hitam dan coklat dan terlihat seperti garis yang berwarna kuning terdapat disisi kiri dan kanan thorax, terdapat rambut sekutelar (Gambar 2c), Abdomen beruas, berwarna

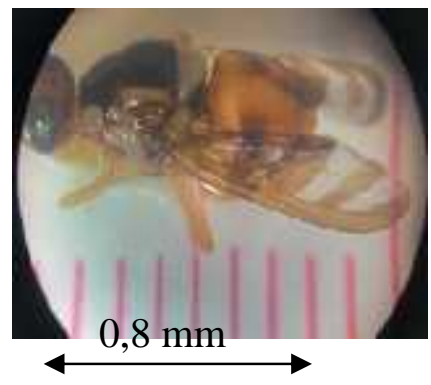

a. Gambar utuh

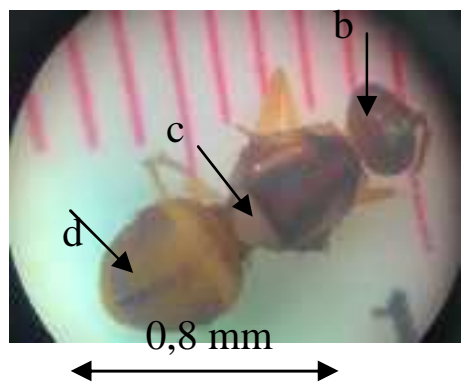

b.Caput c.Thorax d. Abdomen

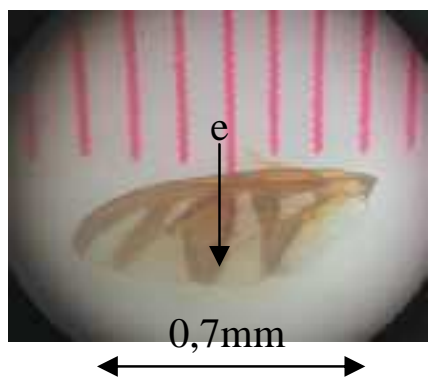

e. Sayap

Gambar 2. Bactrocera umbrosa Fabricius (dok.pribadi, perbesaran 10x)

\section{Bactrocera latifrons Handel.}

Morfologi Bactrocera latifrons ditandai dengan adanya bercak facial besar berbentuk oval (Gambar 3b). Lobus postpronotal dan notopleura berwarna kuning, bagian skutum pada toraks berwarna hitam tidak mengkilat. Terdapat lateral postsutural vittae, namun tidak mempunyai medial postsutural vittae. Terdapat bulu supra alar, bulu preskutelar dan sepasang bulu skutelar (Gambar 3c.), Abdomen didominasi warna merah bata hingga oranye. Tidak terdapat garis medial memanjang pada terga (Gambar 3d) dan Sayap berpola dengan selaput tipis dan sangat transparan (Gambar $3 e$ ), ciri - ciri yang sama juga disebutkan oleh Siwi et al. (2006). 


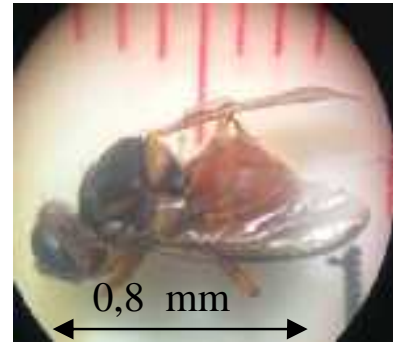

a. Gambar utuh

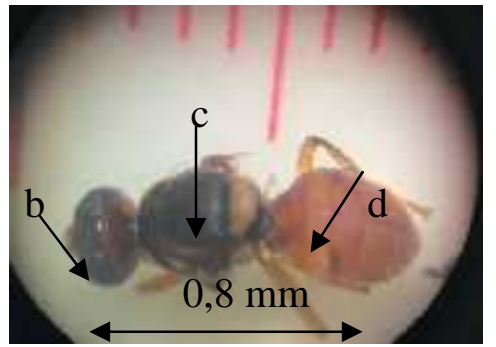

b.Caput c.Thorax

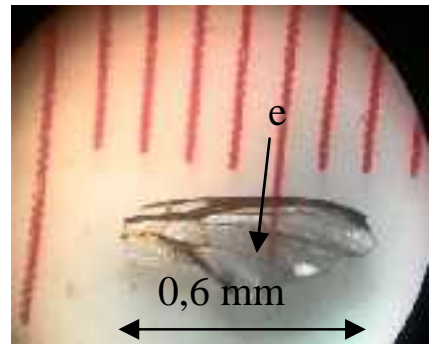

e. Sayap

Gambar 3 Bactrocera latifrons Handel (dok. pribadi, perbesaran 10x)

Komposisi jenis lalat buah pada setiap jenis perangkap atraktan di setiap lokasi

Komposisi jenis lalat buah yang terperangkap pada setiap jenis perangkap dengan bahan atraktan yang berbeda pada lokasi penelitian disajikan dalam tabel 1 berikut :

Tabel 1. Komposisi jenis, kelimpahan jenis dan dominasi jenis Bactrocera sp. Pada setiap jenis perangkap.

\begin{tabular}{|c|c|c|c|c|c|c|c|}
\hline $\begin{array}{l}\text { Lokasi } \\
\text { altitude }\end{array}$ & $\begin{array}{c}\text { Jenis } \\
\text { perangkap }\end{array}$ & $\begin{array}{c}\text { Jenis lalat } \\
\text { buah }\end{array}$ & $\begin{array}{c}\text { Jumlah / } \\
\mathbf{P i}\end{array}$ & Ln Pi & $\mathbf{H}^{\prime}$ & R1 & D \\
\hline \multirow{5}{*}{$\begin{array}{l}\text { Ndengga } \\
\text { Rongge } \\
=913 \mathrm{~m} \\
\mathrm{dpl}\end{array}$} & E0 & 0 & 0 & 0 & 0 & 0 & 0 \\
\hline & E1 & B.papayae & 79 & 0,86 & 0,129 & 0,77 & 0,74 \\
\hline & E2 & B.papayae & 13 & 0,14 & 0,275 & 0,61 & 0,02 \\
\hline & E3 & 0 & 0 & 0 & 0 & 0 & 0 \\
\hline & & & 92 & & & & \\
\hline \multirow{7}{*}{$\begin{array}{c}\text { Lokoboko } \\
=698 \mathrm{~m} \\
\mathrm{dpl}\end{array}$} & E0 & 0 & 0 & 0 & 0 & 0 & 0 \\
\hline & E1 & B.papayae & 60 & 0,55 & 0,33 & 2,76 & 0,30 \\
\hline & & B.umbrosa & 9 & 0,08 & 0,20 & 2,54 & 0,01 \\
\hline & E2 & B.papayae & 30 & 0,27 & 0,35 & 2,71 & 0,07 \\
\hline & E3 & B.papayae & 7 & 0,06 & 0,16 & 2,49 & 0,00 \\
\hline & & B.laitfrons & 3 & 0,02 & 0,07 & 2,09 & 0,00 \\
\hline & & & 109 & & & & \\
\hline
\end{tabular}

Keterangan :

$\begin{array}{llll}\text { E0 } & : \text { Etanol (Kontrol) } & \text { E2 } & : \text { Estrak daun selasih } \\ \text { E1 } & : \text { Ekstrak biji pala } & \text { E3 } & : \text { Ekstrak buah cengkeh }\end{array}$

Tabel 1. memperlihatkan hasil tangkapan setiap jenis perangkap disetiap lokasi. Terperagkapnya 3 jenis lalat buah menandakan bahwa ragam jenis lalat buah di lokasi penelitian masih rendah $\left(\mathrm{H}^{\prime}<1\right)$ jika dibandingkan dengan beberapa lokasi penelitian di daerah lain. Penelitian Sunarno dan Popoko (2013) di Jawa Barat 
menemukan 98 jenis lalat buah. Beberapa penelitian lain menemukan jenis lalat buah Jenis B.papayae terperangkap pada setiap jenis perangkap kecuali pada kontrol dan perangkap E3 dikentinggian $913 \mathrm{mdpl}$, kondisi ini mengindikasikan bahwa keberadaan B.papayae di alam lebih melimpah dibandingkan dengan jenis yang lain meskipun rataan nilai indeks kelimpahan masih tergolong rendah

Berdasarkan tabel 1 tangkapan lalat buah perlokasi, terlihat bahwa hasil tangkapan lalat buah di desa Ndengga rongge, Kecamatan Lepembusu Kelisoke, dengan ketinggian tempat $913 \mathrm{~m}$ dpl dan di Kelurahan Lokoboko, Kecamatan Ndona Kabupaten Ende dengan ketinggian tempat $698 \mathrm{~m}$ dpl, cukup berfluktuasi pada setiap perangkap yang di pasang dengan ekstrak yang digunakan. Menurut Ye et al., (2007), fluktuasi populasi lalat buah terjadi karena faktor iklim (abiotik) berupa suhu, curah hujan, jumlah hari hujan, kelembaban, dan sinar matahari. Faktor suhu dan kelembaban dapat memengaruhi fluktuasi populasi lalat buah di lapangan, karena dapat memengaruhi perkembangan dan reproduksi lalat buah. Sedangkan curah hujan dan jumlah hari hujan yang tinggi dapat menyebabkan populasi lalat buah meningkat (Herlinda dkk., 2008). Selain faktor abiotik, faktor biotik juga dapat mempengaruhi fluktuasi populasi lalat buah. Faktor biotik berupa fenologi tanaman inang, potensi inang lain, serta musuh alami juga berperan terhadap fluktuasi populasi lalat buah pada lahan pertanaman. Faktor inang merupakan faktor utama lain yang mempengaruhi fluktuasi lalat buah di lahan (Ye dan Liu, 2005). Lalat buah merupakan hama yang sifatnya polifag, sehingga mempunyai banyak inang lain selain inang yang utama (Froerer et al, 2010). Lalat buah yang menyerang buah-buahan musiman, akan mempunyai fluktuasi populasi yang beragam dan erat hubungannya dengan keberadaan buah dari inang tersebut (Ginting, 2009).

Tabel 1. juga memperlihatkan hasil keragaman $\left(\mathrm{H}^{1}\right)$, kelimpahan $\left(\mathrm{R}_{1}\right)$, dan dominasi (D) dari ke dua lokasi yang rendah. Kondisi tersebut di perkuat dengan temuan di lapangan bahwa hanya di temukan 1 jenis lalat buah yang menyerag tanaman tomat di Desa Ndengga rongge kecamatan Lepembusu Kelisoke dan 3 jenis lalat buah yang menyerang tanaman tomat di Kelurahan Lokoboko Kecamatan Ndona. Sementara itu kelimpahan populasi juga masih dalam kategori rendah yang artinya populasi lalat buah di lapangan masih dapat di toleran oleh lingkungan. Tingkat dominasi jenis yang rendah menandakan bahwa lingkungan masih dalam kondisi yang stabil. Kondisi yang stabil tersebut dikarenakan kemungkinan masih diberlakukan pengendalian secara alami dan juga dengan menggunakan curah hujan, hal tersebut dapat menekan perkembangan dan populasi lalat buah (Magurran, 1998) Tingkat efektivitas beberapa jenis perangkap lalat buah yang pasang pada pertanaman tomat (Tabel 2). 
Tabel 2. Efektivitas setiap jenis perperangkap.

\begin{tabular}{cccc}
\hline Jenis perangkap & & Jenis lalat buah & Populasi \\
\hline E0 & 0 & 0 & 0 \\
E1 & 2 & Bactrocera papayae & 139 \\
& & Bactrocera umbrosa & 9 \\
E2 & 1 & Bactrocera papayae & 93 \\
E3 & 2 & Bactrocera papayae & 7 \\
& & Bactrocera latifrons & 3 \\
& & & \\
\hline
\end{tabular}

Berdasarkan tabel 2 efektivitas setiap jenis perperangkap, dari setiap jenis perangkap memiliki spesifikasi atau kemampuan untuk menarik lalat buah dengan jenis yang berbeda sehingga memberikan hasil tangkapan yang berbeda. Hal ini di dukung dengan hasil temuan di lapangan bahwa pada jenis perangkap yang digunakan yakni E1 (pala) dapat memerangkap dua jenis lalat buah yaitu Bactrocera papayae dan Bactrocera umbrosa, E2 (selasih) hanya dapat memerangkap satu jenis yakni
Bactrocera papayae sedangkan E3 (cengkeh) dapat memerangkap dua jenis lalat buah yakni Bactrocera papayae dan Bactrocera latifrons. Kondisi ini mengindikasikan bahwa jenis perangkap dengan menggunakan ekstrak biji pala (E1) dan buah cengkeh (E3) lebih baik dibandingkan dengan Ekstrak biji selasih (E2). Namun secara statistic dapat dibuktikan tingkat signifikasinya sebagai berikut

Tabel 3 Analisis statistik efektivitas setiap jenis perangkap.

\begin{tabular}{cccccc}
\hline \multirow{2}{*}{ Perlakuan } & \multicolumn{3}{c}{ Hasil tangkapan } & \multirow{2}{*}{ Total } & \multirow{2}{*}{ rata-rata } \\
\cline { 2 - 4 } & I & II & III & & 0 \\
E0 & 0 & 0 & 0 & 0 & b \\
E1 & 87 & 33 & 28 & 148 & $49,33 \mathrm{a}$ \\
E2 & 24 & 12 & 7 & 43 & $14,33 \mathrm{~b}$ \\
E3 & 2 & 3 & 5 & 10 & $3,33 \mathrm{~b}$ \\
\hline jumlah & 113 & 48 & 40 & 201 & 66,99 \\
\hline
\end{tabular}

Keterangan : data telah di transformasi menggunakan transformasi akar kuadrat.

Huruf yang sama pada baris yang berbeda menyatajan bahwa perlakuan tersebut tidak berbeda nyata.

Tabel 3 menyatakan bahwa E1 (ekstrak pala) merupakan ekstrak terbaik untuk memerangkap lalat buah karena hasil tangkapan tertinggi dan berbeda nyata terhadap jenis atraktan lainnya, kondisi yang demikian terjadi karena kandungan metil eugenol pada biji pala 1,8 \% lebih besar dari selasih $(80 \%)$ dan cengkeh $(64 \%)$ sedangakan E2 (ekstrak selasih) dan E3 (ekstrak cengkeh) memiliki aktivitas tidak berbeda nyata pada uji BNT 5\%.. Hasil penelitian ini bertolak belakang dengan hasil penelitian Zubaidah (2008) yang meneliti daya atraktan ekstrak daun selasih (Ocimum santum) dan biji pala (Myristica fragant) terhadap lalat buah 
(Bactrocera $\mathrm{sp}$ ) pada skala laboratorium yang memperlihatkan hasil bahwa ekstrak daun selasih merupakan atraktan terbaik dengan tingkat atraktan $11,6 \%$ lebih tinggi dari ekstrak biji pala. Perbedaan ini dapat terjadi dikarenakan penelitian ini dilakukan di lapangan dimana terdapat factor-faktor pengendali lain selain perlakuan. Namun demikian penelitian ini membuktikan bahwa penggunaan jenis atraktan yang berbeda dapat menunjukan kemampuan yang berbeda dalam memerangkap lalat buah.

\section{SIMPULAN}

Berdasarkan data yang telah diperoleh selama kegiatan di lapangan, maka dibuat kesimpulan sebagai berikut :

1. Terdapat tiga jenis lalat buah yang terperangkap pada 3 jenis atraktan di pertanaman tomat yaitu Bactrocera papaya, Bactrocera umbrosa Fabricius dan Bactrocera latifrons Handel.

2. Indeks keragaman jenis Bactrocera sp. di lokasi penelitian masih tergolong rendah. Kelimpahan tertinggi adalah B.papayae dengan rata-rata nilai $H^{\prime}=1,86$ dan terendah adalah B.latifrons $\left(\mathrm{H}^{\prime}=0,07\right)$. Tidak terdapat dominasi jenis di lokasi penelitian yang memandakan bahwa kondisi ekosistem masih stabil.

3. Ekstrak biji pala merupakan bahan perangkap atraktan terbaik sebagai bahan atraktan lalat buah dilapang.

\section{UCAPAN TERIMAKASIH}

Penulis mengucapkan terimakasih kepada semua pihak yang telah membantu sehingga penelitian ini dapat berjalan dengan baik, khususnya bagi petani tomat di lokasi penelitian yang telah bersedia menjadikan lahan pertanamannya sebagai area pemasangan perangkap.

\section{DAFTAR PUSTAKA}

Balittro. 2008. Perangkap Lalat Buah.

http://www. pustaka deptan.go.id. Diakses

4 Desember 2016.

Drew. 1994. The Bactrocera dorsalis complex of fruit flies (Diptera: Tephritidae; Dacinae) in Asia. Bulletin of Entomological Research. 2.

Froerer KM, Peck SL, McQuate GT, Vargas RI, Jang EB, McInnis DO. 2010. Long-distance movement of Bactrocera Dorsalis (Diptera: Tephritidae) in Puna, Hawaii: How far can they go?. American Entomologist. 56(2).

Ginting, R. 2009. Keanekaragaman lalat buah (Diptera: Tephritidae) di Jakarta.Depok. dan Bogor sebagai bahan kajian penyusunan analisis resiko hama.[Tesis]. Bogor: Fakultas Pertanian. Institut Pertanian Bogor.

Gomez, K.A., Gomez, A.A. 2010. Prosedur Statistik untuk Penelitiaan Pertanian. Ed.2. Universitas Indonesia Press.

Herlinda, S., Zuroaidah., Pujiastuti, Y., Samad S., Adam, T., 2008. Spesies lalat buah yang menyerang sayuran Solanaceae dan Cucurbitaceae di Sumatera Selatan. Jurnal Hortikultura 18(2) : 212-220.

[ICMPFF] International Centre for the Management of Pest Fruit Flies. 2012. Fruit Flies of Indonesia: Their Identification, Pest Status and Pest Management. Brisbane(AU): Griffith University.

Kardinan, A. 2003. Pengendalian Hama Lalat Buah. Bogor: Agromedia Pustaka.

Kardinan, A. 2007. Pengaruh Campuran Beberapa Jenis Minyak Nabati Terhadap Daya Tangkap Lalat Buah. Bogor: Agromedia Pustaka 
Khaeruddin. 2015. Identifikasi Lalat Buah (Diptera: Tephritidae) di Beberapa Kabupaten di Provinsi Sulawesi Barat [tesis]. Bogor (ID): Institut Pertanian Bogor

Lubis, W.H. 2018. Identifikasi Lalat Buah (Bactrocera spp.) pada Beberapa Jenis Tanaman Buah-buahan di Kabupaten Deli Serdang dan Kabupaten Karo, Sumatera Utara. Skripsi. Depatremen Perlindungan Tanaman. Institut Pertanian Bogor.

Magurran AE. 1988. Ecological Diversity and Its Measurement. New Jersey: Princeton University Press.

Marpaung AYA, Pangestiningsih Y, Pinem MI. 2014. Survei pengendalian hama terpadu lalat buah Bactrocera spp. pada tanaman jeruk di tiga kecamatan Kabupaten Karo. Jurnal Online Agroteknologi. 2(4): 13161323.

Siwi, S, S., Hidayat, P., Suputa. 2004. Taksonomi dan Bioekologi Lalat Buah Penting di Indonesia (Diptera : Tephritidae).Balai Besar Penelitian dan Pengembangan Bioteknologi dan Sumber Daya Genetik Pertanian

Sunarno. 2011. Ketertarikan Serangga Hama Lalat Buah terhadap Berbagai Papan

Perangkap Berwarna sebagai Salah Satu Teknik Pengendalian. Jurnal Agroforestri 6(2): 131-134.

Sunarno. Popoko, S. 2013. Keragaman Jenis Lalat Buah (Bactrocera spp) di Tobelo Kabupaten Halmahera Utara. Jurnal Agroforestri 8: 269-276.

Suputa., Cahyanti., Kustaryati, A., Railan, M., Issusilaningtyas., Taufiq, A. 2007. Pedoman Identifikasi Lalat Buah (Diptera: Tephritidae). Yogyakarta : UGM.

Wahyuni, S. 2017. Parasitoid community structure of leafnminer Liriomyza spp. (Diptera: Agromyzidae) and the rate of parasitazion on vegetable crops in Lesser Sunda Islands, Indonesia

Ye, H., Liu, J, H. 2005. Population dynamics of the oriental fruit fly, Bactrocera dorsalis (Diptera: Tephritidae) in the Kunming area, southwestern China. Insect Science 12 (5): 387-392.

Ye, H., Liu, J, H. 2007. Population dynamics of oriental fruit fly Bactrocera dorsalis (Diptera: Tephritidae) in Xishuangbanna, Yunnan Province, China. Frontiers in Agriculture of China 1(1): 76-80.

Zubaidah. 2008. Daya Atraktan Ekstrak Daun Selasih (Ocium Santum) dan Biji Pala (Myristica fragrant) Terhadap Lalat Buah (Bactrocera sp). 